Paul Cairney, University of Aberdeen, paul.cairney@abdn.ac.uk

Political Studies Review Final Submission May 11 2012. The definitive version is available at www.wileyonlinelibrary.com

\title{
Complexity Theory in Political Science and Public Policy
}

\begin{abstract}
Advocates of complexity theory describe it as a new scientific paradigm. Complexity theory identifies instability and disorder in politics and policymaking, and links it to the behaviour of complex systems. It suggests that we shift our analysis from individual parts of a political system to the system as a whole; as a network of elements that interact and combine to produce systemic behaviour. This article explores the use of complexity theory in public policy, highlighting a small literature using the language of complexity directly to describe complex policymaking systems, and a larger literature identifying complexity themes. It then highlights the main problems to be overcome before complexity theory can become truly valuable in politics and policymaking.
\end{abstract}

\section{Introduction}

Advocates of complexity theory describe it as a new scientific paradigm (Mitchell, 2009: $\mathrm{x})$. They suggest that it can change the way we think about, and study, the natural and social world. It marks a scientific revolution; a revolutionary break from the 'reductionist' approach. Complexity theory suggests that we shift our analysis from individual parts of a system to the system as a whole; as a network of elements that interact and combine to produce systemic behaviour that cannot be broken down merely into the actions of its constituent parts. Rather, the aim is identify what types of systemic outputs occur when its members follow the same basic rules, and how sensitive the system is, or what small changes in rules will produce profound changes in systemic behaviour. The metaphor of a microscope or telescope, in which we zoom in to analyse individual components or zoom out to see the system as a whole, sums up this shift of approach. Far reaching examples of emergent behaviour in the natural and social world from bees swarming, to thoughts and feelings emerging from cells and neurons in the brain, and emerging forms of cooperation among social groups - also highlight its wide application. Indeed, advocates of complexity theory highlight its strong appeal across the sciences as a whole and its unusual ability to foster a meaningful degree of interdisciplinarity.

Complexity theory has been applied to the study of neuroscience, ecology, epidemiology, memory coding, computer science and metabolic networks (Newman et al, 2006; beim Graben et al, 2008; Motter et al, 2002; Arenas et al, 2008; Moura et al, 2003). It has some strong support in the social sciences (including Byrne, 1998), has attracted special journal issues (including Public Management Review and Political Analysis - see Teisman and Klijn, 2008; Mahoney and Goertz, 2006), has been used to understand international relations (Jervis, 1998), public policy and policymaking institutions (Geyer and Rihani, 2010; Room, 2011) and has been used by think tanks, academics and practitioners to recommend new forms of policymaking (Hallsworth and Rutter, 2011; Room, 2011: 306-18; Sanderson, 2006; 2009; Geyer, 2012). It is also used more widely 
in many areas of political science without necessarily being branded as 'complexity' work. Consequently, it is a theory that should be taken very seriously in political science.

The aim of this article is to provide a brief, broad overview of the topic; to assess the value of complexity theory in political science in general, but also focus on its links to policy theory and practice in particular. First, it provides a definition of complexity theory and identifies its key tenets. Second, it describes how complexity theory is applied in political science (explicitly and directly, or implicitly and indirectly). Third, it highlights the challenges that we face when seeking to combine insights from the natural and social sciences into a theory that informs our understanding of political science (see also Cairney, 2010a). Our main concern may be that the language of 'complexity' is used too loosely, without yet providing: a common definition to tie together a wide range of studies; a convincing way to adapt complexity theory to political science without presenting a deterministic argument; or, a way to use its insights to give meaningful advice to policymakers. The article shows briefly how these concerns can be addressed.

\section{What is Complexity Theory?}

Complexity theory is generally sold as a new approach to science in which we identify (then explain) systems or processes that lack the order and stability required to produce universal rules about behaviour and outcomes. When applied to the sciences as a whole, it is described as a revolutionary break from the 'reductionist' approach to science and the 'paradigm of order' (Mitchell, 2009: x; Geyer and Rihani, 2010: 12), or as a new 'way of thinking' and 'seeing the world'; as a 'world of instability and fluctuations' when in the past it was seen as 'stable' (Newton's laws are often used as an example of the old way of thinking) (Mittleton-Kelly, 2003: 26; Sanderson, 2006: 117).

In political science, it is mostly used to challenge particular brands of 'positivism' which present a 'vision of society based on order, laws and progress' (Geyer and Rihani, 2010: 5); to suggest that 'quantitative and reductionist methodologies' may be useful to explain topics such as elections with 'rules and orderly structures', but not issues which contain unpredictable political events, significant levels of uncertainty and ambiguity (Geyer and Rihani, 2010: 74-5) or factors outside of the control of policymakers (Room, 2011: 6-7; see Klijn, 2008: 314 on 'wicked', or apparently intractable, policy problems). Many accounts also use it to challenge their idea of rational choice theory (Little, 2008: 29-30; Lewis and Steinmo, 2008: 15-20; 2010: 237; Geyer and Rihani, 2010: 5). Thus, it may be used increasingly to support the 'backlash' against this approach which (at least in the 1990s) looked like it might become paradigmatic (Hindmoor, 2011: 191). More broadly, it may mark a return of sorts to more 'holistic' and less 'individualistic' accounts of political behaviour. ${ }^{\mathrm{i}}$

Its distinctiveness derives less from its identification of complexity in a broad sense and more from its focus on complex systems (in other words, it does not merely say that the world is complicated - Little, 2012: 6). It seeks to explain why complex or system-wide behaviour emerges from the interaction between 'large collections of simpler components' (Mitchell, 2009: x; Kernick, 2006; Blackman, 2001). There is considerable variation in the way that the theory is described and used (Mittleton-Kelly, 2003: 23; 
Geyer 2012: 31), but we can identify six main themes regarding how complex systems behave and how we should study them (see Cairney, 2012: 125-6):

1. A complex system cannot be explained merely by breaking it down into its component parts because those parts are interdependent: elements interact with each other, share information and combine to produce systemic behaviour.

2. The behaviour of complex systems is difficult (or impossible) to predict. They exhibit 'non-linear' dynamics produced by feedback loops in which some forms of energy or action are dampened (negative feedback) while others are amplified (positive feedback). Small actions can have large effects and large actions can have small effects.

3. Complex systems are particularly sensitive to initial conditions which produce a long-term momentum or 'path dependence'.

4. They exhibit emergence, or behaviour that evolves from the interaction between elements at a local level rather than central direction. This makes the system difficult to control (and focuses our attention on the rules of interaction and the extent to which they are adhered to).

5. They may contain 'strange attractors' or demonstrate extended regularities of behaviour which are 'liable to change radically' (Geyer and Rihani, 2010: 39; Bovaird, 2008: 320). They may therefore exhibit periods of 'punctuated equilibria' - in which long periods of stability are interrupted by short bursts of change.

6. The various problems that complexity theory seeks to address - such as predicting climate change, earthquakes, the spread of disease among populations, the processing of DNA within the body, how the brain works, the growth of computer technology and artificial intelligence, and the behaviour of social and political systems - can only be solved by interdisciplinary scientific groups (Mitchell, 2009: $\mathrm{x})$.

\section{Complexity Theory and the Public Policy Literature}

The complexity and public policy literature consists of two main strands: (a) a relatively small strand that engages directly and explicitly with complexity theory when analysing public policy, arguing that policymaking systems are complex systems (in other words, complexity is often not used as just another natural science metaphor); and, (b) a much wider range of studies, central to the public policy literature, that highlight complex system characteristics without necessarily using the language of complexity.

\section{(A) Policymaking Systems are Complex Systems}

Complexity theory highlights the problems that arise when policymakers do not recognise the complex nature of their policy environments. Geyer and Rihani (2010: 29) link the pursuit of 'human order' to a myriad of failed attempts to control the social world, from socialism in the Soviet Union to the pursuit of a free market ideology in the 'Third World' and 'the 1980s and 1990s emphasis on 'centralised public management"'. They do not identify a complete lack of order or control in political systems. Rather, they describe a 'partial order' in which there are both 'orderly and chaotic behaviours'. Some phenomena can be reduced to their constituent parts and modelled to aid prediction, while 
others may not, producing uncertainty and a reliance on probabilistic prediction. They suggest that these elements have been ignored by policymakers in the UK who were too driven by the idea of order, as it related to government (by maintaining rigid hierarchies and producing top-down, centrally driven policy strategies) or to the dominant approach to policy, such as new public management reforms in which the application of private sector ideas to the public sector 'required a radical increase in performance indicators so that the centre could oversee and direct what the local and decentralised actors were doing' (2010: 23; Geyer, 2012: 21). The outcome may be policy failure and demoralised policymakers (Room, 2011: 7).

In this context, complexity theory may provide four key policymaking insights (Teisman and Klijn, 2008: 288; see also Cairney, 2012: 126; Blackman, 2001; Kernick, 2006; Sanderson, 2006; 2009). The first is that law-like behaviour is difficult to identify because the policy process is 'guided by a variety of forces', suggesting that $\mathrm{X}$ will only have an effect on $\mathrm{Y}$ under particular conditions that are difficult to specify. A policy that was successful in one context may not have the same effect in another. We need to know why it was successful in that instance, but the idea of complexity is that so many variables are relevant (and tiny variations in them can matter) that it is difficult to account for them all. The second is that systems appear to have 'self-organizing capacities', making them difficult to control; the effect of an internal or external force may be large or small and this is impossible to predict from the force alone. This lesson could be learned by policymakers who otherwise would be surprised that their policy interventions did not have the desired effect. The third relates to the metaphor of the 'fitness landscape' or 'surroundings in which living beings exist and behave'. This landscape, which provides the context for the choices of agents, is unstable and often changes rapidly. Therefore, agents or organisations must adapt quickly and not rely on a single policy strategy (2008: 289; see also Mitleton-Kelly, 2003: 35-6). The fourth is that actors within complex systems can create 'their own perception of what they want and how to behave in the landscape they are in' (2008: 289). However, policymakers often seek to concentrate more power at the centre rather than seek to understand their policymaking environment.

Overall, Teisman and Klijn (2008: 294) point to a way of understanding policymaking as a process that defies simple solutions. For example, while top-down implementation models might link success to simplicity, to one clear goal and a select number of officials to carry it out, complexity theory suggests that this process could not be separated and made immune from its wider context. Rather, implementing officials will have to adapt policy in response to this dynamic process (see also Bovaird, 2008: 339). Mitleton-Kelly (2003: 41) places more emphasis on self-organisation and emergent behaviour as it relates to the whole system. In this sense, we are not just talking about individuals adapting to their environments because 'a system may need to be studied as a complete and interacting whole rather than as an assembly of distinct and separate elements'. In other words, breaking the process down into a system's constituent parts (including the actions of individuals within it) may undermine explanation. We discuss such tensions of explanation, between the system and individuals, below. 


\section{(B) Complexity Themes in Public Policy ${ }^{\mathrm{ii}}$}

The complexity literature has its own jargon to demonstrate that political systems exhibit the characteristics of complex systems. Yet, it also has resonance with several theories in political science. First, the link between complexity theory and discussions of path dependence is strong, and the focus on 'sensitivity to initial conditions' is a key tenet of historical institutionalism (although we need to be very careful with such comparisons). ${ }^{\text {iii }}$ Path dependence suggests that when a commitment to a policy has been established and resources devoted to it, over time it produces 'increasing returns' (when people adapt to, and build on, the initial decision) and it effectively becomes increasingly costly to choose a different path (Pierson, 2000; compare with Room, 2011: 7-8; 16-8). In many cases these 'returns' are associated with the establishment and maintenance of institutions. Historical institutionalist studies often define institutions as 'the formal rules, compliance procedures, and standard operating procedures that structure conflict' (Hall in Thelen and Steinmo, 1992: 2). The focus of analysis becomes the details of a 'critical juncture' and the timing of decisions is crucial, because it may be the order of events that sets policy on a particular path. We identify both inertia and unpredictability, as relatively small events or actions can have a huge and enduring effect on policy change which is very difficult to reverse. Both, Pierson (2000: 253) and Room (2011: 16) adopt the same language (the 'Polya urn') and examples (such as the QWERTY keyboard) to describe the unpredictability of events and initial choices followed by subsequent inflexibility when the rules governing systemic behaviour become established and difficult (but not impossible) to change.

Second, a key type of punctuated equilibrium theory (as articulated by Jones and Baumgartner, 2005; Baumgartner and Jones, 2009; Workman et al, 2009) employs some of the language of complexity to explain a shift in group-government relationships, from the simple 'clubby days' of early post-war politics to 'complex relationships' at multiple levels of government and among a huge, politically active population (Heclo, 1978: 94; 97; Baumgartner and Jones, 1993: 177-8; Jordan, 1981: 98; Richardson, 2000: 1008; see also Bovaird, 2008: 321 and Klijn's 2008: 302 description of complex systems essentially as a series of subsystems, all of which have their own rules of behaviour and external forces to deal with). The 'general punctuation hypothesis' demonstrates, in a study of information processing, that policy processes exhibit non-linear dynamics and punctuated equilibria. ${ }^{\text {iv }}$ Jones and Baumgartner (2005: 7) define information processing as the 'collecting, assembling, interpreting and prioritizing [of] signals from the environment'. Policymakers are effectively surrounded by an infinite number of 'signals', or information that could be relevant to their decisions (from, for example, interest groups, the media or public opinion). Since they are 'boundedly rational' (Simon, 1976) and do not have the ability to process all signals, they must simplify their decision-making environment by ignoring most (negative feedback) and promoting few to the top of their agenda (positive feedback).

Negative feedback may produce long periods of equilibrium since existing policy relationships and responsibilities are more likely to remain stable and policy is less likely to change when the issue receives minimal attention from policymakers. Positive 
feedback may produce policy 'punctuations' because when policymakers pay a disproportionate amount of attention to an issue it is more likely that policy will change dramatically. This is particularly the case following a 'bandwagon effect' in which policymakers and interest groups at multiple levels of government all pay attention to an issue at the same time, often seeking to contribute to finding new ways to address old problems and challenge the right of one organisation to command policy responsibility. The 'selective attention' of decision-makers or institutions explains why issues can be relatively high on certain agendas, but not acted upon; why these powerful signals are often ignored and policies remain stable for long periods. Policymakers are unwilling to focus on certain issues, either because ideology precludes action in some areas, there is an established view within government about how to address the issue, or because the process of acting 'rationally' (making explicit trade-offs between a wide range of decisions) is often unpopular. They are also unable to give issues significant attention, because the focus on one issue means ignoring 99 others. Change therefore often requires a critical mass of attention to overcome the conservatism of decision-makers and shift their attention from competing problems (Jones and Baumgartner, 2005: 19-20; 48-51). If the levels of external pressure reach this tipping point, they cause major and infrequent punctuations rather than smaller and more regular policy changes: the burst in attention and communication becomes self-reinforcing; new approaches are considered, different 'weights' are applied to the same categories of information; policy is driven ideologically by new actors; and/ or the 'new' issue sparks off new conflicts between political actors (2005: 52; 69). Information processing is characterised by 'stasis interrupted by bursts of innovation' and policy responses are unpredictable and episodic rather than continuous (2005: 20).

Third, complexity theory's focus on emergent behaviour in the absence of central control evokes the literatures on implementation and governance which explore the problems that central governments face when they do not recognise the extent to which policy changes as it is implemented (Cairney, 2009; Butler and Allen, 2008; Klijn, 2008; compare with Marsh, 2008). The level of interdependence governments share with implementing organisations has prompted the identification of 'self-organizing networks' (Rhodes, 1997: 50) and images of 'bottom-up' implementation through self-selecting clusters of organizations in which a variety of public and private organizations cooperate (Barret and Fudge, 1981; Hjern and Porter, 1981). While there is some scope for central governments to control implementation, most notably through cross-cutting targets linked to the control of public expenditure (Richards and Smith, 2004), Lipsky's (1980) classic analysis of 'street-level bureaucracy' suggests that, since public sector professions are subject to an immense range of (often unclear) requirements laid down by regulations at the top, they are powerless to implement them all successfully. Instead, they establish routines and use rules of thumb to satisfy a proportion of central government objectives while preserving a sense of professional autonomy necessary to maintain morale. While such problems have prompted governments in the past to embrace new public management (or the application of private business management methods to the public sector) and seek to impose order through hierarchy and targetry, such implementing structures may not be amenable to such direct control. 


\section{Complexity Theory: Problems and Solutions}

\section{What Exactly is Complexity Theory?}

The first difficulty with complexity theory is that it is difficult to pin down when we move from conceptual to empirical analysis. While we may find similar discussions in a wide range of texts in the literature, many accounts (such as Room, 2011: $327 \mathrm{fn.} \mathrm{2.1}$; Geyer, 2012: 31) still highlight terminological and conceptual variation, and often link it to the novelty of complexity theory. Its appeal in the sciences may be because it means different things to different people, suggesting that initial enthusiasm and crossdisciplinary cooperation (when focused on broad concepts) may be replaced by growing dissatisfaction, scepticism and uncertainty about a core subject of common study (when focused on applying those concepts).

This may be a particular problem in the social sciences because human behaviour, or 'the capacity to reflect and to make deliberative choices and decisions among alternative paths of action', makes the social world a different object of study than the physical world (Mitleton-Kelly, 2003: 25-6; see also Padgett and McLean, 2006: 1464 - 'imitation of biological science by the social sciences should never be slavish: social systems have no genes, and social systems have consciousness'). Consequently, its application to public policy is often unclear and the term 'complexity' (like the term 'evolution') is often used very loosely or denotes a metaphor or analogy (Mitleton-Kelly, 2003: 26; Kernick, 2006: 389; Bovaird, 2008: 321). When we try to use the term more directly, to identify a real, complex political system we find less agreement about what a complex system is. Jervis (1998: 5-6) prefers to define by example - 'I know it when I see it'. However, different people are clearly seeing different things, identifying complex systems from studies of local social housing projects (Shine, 2006) to large international systems (Jervis, 1998). Indeed, we face the need to examine how smaller systems operate within larger complex systems (Geyer and Rihani, 2010: 53 call this the 'cascade of complexity'), which undermines the neat telescopic analogy.

This is not an unusual problem, since most terms in the social science literature often defy common definition, while many vague terms such as 'new institutionalism' are used to represent a common focus (Cairney, 2012: 70). In such cases, our aim is to identify a shared and distinctive scientific endeavour. This may require the development of closeknit interdisciplinary teams consisting of members of the natural and social sciences, which meet regularly to think through the details of theory development, as a way to overcome conceptual and methodological differences. There may be great value in applying natural science ideas to the social sciences (and vice versa), but this requires us to go beyond using complexity as a metaphor and considering what processes such as 'emergence' look like in practice.

\section{Deterministic Arguments?}

The second is that complexity theory often appears to present a deterministic argument. The potential danger is that if the complex system is predominantly the causal factor then we lose sight of the role that policymakers play; there may be a tendency to treat the 
system as a rule-bound structure which leaves minimal room for the role of agency. This is a common concern regarding systems research - they often seem to have their own logics which 'operate in some sense independent of - and over the heads of - the actors themselves' (Hay, 2002: 102). It would be tempting (but misleading) to contrast this picture with interpretive social science which rejects the assumption of structural constraint. Interpretive accounts explore how agents perceive their decision-making environments; how they reproduce, accept or challenge the structural, institutional and wider systemic constraints that they appear to face when making decisions. Indeed, they may even reject terms such as 'institution' and 'rule' because they imply a sense of permanence or common understanding that has not been demonstrated (Bevir and Rhodes, 2003; 2006).

A more positive treatment of complexity suggests that it gives us two perspectives that represent Giddens' 'two sides of the same coin ... If we look at social practices in one way, we can see actors and actions; if we look at them another way we can see structures' (Craib, 1992: 3 on Giddens, 1984). On one side, we have 'self-organizing landscapes' (Teisman and Klijn, 2008: 289) or complex systems that adapt and change behaviour; behaviour is 'emergent' from the processes or interactions within systems and is not readily broken down to the agents within it (Mitleton-Kelly, 2003: 28). On the other, we have the 'self-referential behaviour' of agents, reacting to 'external forces and changes' but also, 'creating their own perception of what they want and how to behave in the landscape they are in' (Teisman and Klijn, 2008: 289; see also Haynes, 2008: 402) ${ }^{\mathrm{v}}$. Consequently, there is scope to explore interpretive accounts of complexity if our aim is to understand how agents interpret, adapt to and influence their decision-making environment. In-depth qualitative studies of practitioners, combining significant periods of observation with multiple interviews, may be usefully combined with mathematical modelling (Cairney, 2010b). Such accounts would recognise the importance of agency and meaning, but also identify the limits to agency, when the actions of others - and factors beyond their control - limit their ability to act in particular ways. They would also stress the importance of examining patterns which emerge from the interactions between large numbers of people and institutions (and are difficult to reduce simply to the role of individuals).

\section{What Does Complexity Mean to Policymakers?}

There have been notable attempts by academics and think tanks to translate complexity theory insights into meaningful lessons for policy practitioners, producing three main issues. First, we can generally detect a normative side which often rejects the appropriateness of top-down control (in a way reminiscent of 'bottom up' approaches to implementation - Cairney, 2012: 37-8). For example, Geyer and Rihani (2010: 7; 32-4) recommend that 'soft management methods ... replace the outwardly forceful but practically blunt traditional hierarchical hard management methods'. This may involve giving implementing organisations more freedom to learn from their experience and adapt to their environment (2009: 708; Haynes, 2008: 326). Second, we can identify proposals to address the inevitability that policies will produce unintended consequences (and be subject to the unintended consequences of action elsewhere). Sanderson (2009: 706) suggests that the implication of complexity is that we do not know exactly how any 
policy measure will make a difference. Therefore, policymakers should be careful when making an intervention. This suggests a greater use of "trial and error' policy making" and learning from pilot projects (2009: 707; compare with Lindblom, 1959: 86 on incrementalism; see also Sanderson, 2006: 118: 'knowledge of a system's behaviour in the past will provide little guide to likely future behaviour'). Little (2012: 16) suggests that we go further, to accept the inevitability of a degree of 'error' when we design policies, so that we can encourage ways to adapt quickly (rather than merely use the language of 'failure' in retrospect to justify abandoning a policy). Geyer (2012: 32) suggests that we go further still, by fundamentally challenging the way that the UK Government has tried to measure and control policy outcomes, and promoting alternatives (such as the 'complexity cascade').

Third, that translation process is not yet complete. Its recommendations may be too abstract (encourage systemic emergence; encourage co-evolution with the social ecosystem; shift from strategic planning to strategic management), while even the more specific points (support the production of new ideas and ways of working in complex systems; encourage 'subsystems' within organisations to communicate with each other; give delivery organisations the freedom to manage) may seem meaningless or banal to public managers. Room (2011) makes the most notable academic attempt to provide a new 'toolkit' for 'agile' policymakers, arguing that existing approaches are based on a too-simple understanding of the policy environment. Yet, the instructions are often vague, including 'map the landscape' ('is it stable or turbulent'?) and 'model the struggle' ('what would drive the race in a different direction'). The Institute for Government (Hallsworth and Rutter, 2011: 18) recommendations appear more grounded in their regular discussions with practitioners, arguing for example that 'greater awareness of complexity will encourage more informal, inquiring attempts to understand how the policy is being realised - rather than simple performance monitoring'. This suggests that the best hope for complexity research is to develop such 'toolkits' in cooperation with policymakers, since that interaction can produce new ideas and ways of thinking. As Hallsworth and Rutter (2011: 30) recommend: 'the development of policy skills .. needs to be embedded into practice .. [governments need] to ensure that there are continual efforts to develop analytic skills so policy makers can be competent consumers of research, or are able to conduct an organisational analysis, or understand concepts from complexity science like emergence and feedback loops'.

\section{Conclusion: The End or the Beginning for Complexity Theory?}

Complexity theory has the potential to divide a political science audience. For some, it represents a profoundly new way to examine politics; a paradigm shift in the social sciences that will help replace rational choice theory and shift our focus of explanation from individualistic to holistic accounts. Indeed, the review process for this article was particularly interesting, since it demonstrated the strength of feeling among some scholars who suggest that it: represents an idiosyncratic and superficial review of a huge, well established field; makes numerous glaring errors of omission (regarding, for example, Luhmann, Axelrod, Page, Prigogine and the Santa Fe and Brussels schools); and, fails to show the value of complexity theory to concrete empirical work. There is also much unresolved tension within the complexity field about how coherent the field is (should we 
talk rather about many complexity theories?) and the extent to which it has been used properly in political science (how can we compare the 'hard sciences', advancing important mathematical models, with the 'soft sciences' using metaphors in fields such as public management?).

For others, it will be seen as a passing fad. An unsympathetic reader may conclude that complexity theory has little to add to political science, since most of its themes may already be well established in the literatures on institutionalism, punctuated equilibrium, incrementalism and implementation. Complexity theory may complicate the study of public policy without offering something new or its insights may be described as "obvious and "commonsensical"" (Geyer and Rihani, 2010: 186). Indeed, it may compound the tendency towards providing 'new' concepts which produce a lack of clarity regarding their link to old concepts and the extent to which we are describing new phenomena as well as new ideas (Keating, 2009: 301). Yet, when used wisely, we can identify two types of 'added value'.

The first source of potential value is academic. The main advantage of this approach is that it helps us to take the links between the social and natural sciences more seriously (Geyer and Rihani, 2010: 186). Past debates on subjects such as behaviouralism and rational choice theory perhaps centred (often in a rather confusing way) on the argument that it is inappropriate to slavishly import methods from the natural sciences. With complexity theory there is scope for a more meaningful conversation between the sciences rather than the importation of methods and metaphors from the natural to the social, particularly since the social world often provides more fertile ground for complexity research. Indeed, the trend in the physical sciences appears to be to look to the social sciences for the next big breakthrough in theory. Complexity theory applied from the natural to the social sciences may aid our understanding of the policy process but also yield insights into our overall understanding of complex systems (Cairney, 2010b).

The second source of potential regards 'impact'. Complexity theory appears more likely to be used to produce practical advice to practitioners than to inform the wider theological debates on structure and agency that we find in political science. Further, as Room (2011: 306) suggests, complexity may compete well (for example, within government training courses) with 'policy cycle' models based on the division of tasks into discrete stages (see Cairney, 2012: 32-4). In this context, the restatement of themes that are already in good political science currency is less problematic. These points are perhaps being restated because the lessons from 'bottom-up' studies have been lost or ignored, and governments continue to operate in a top-down manner rather than engaging in a more meaningful dialogue between those who design and those who deliver and use public services (Butler and Allan, 2008; Kernick, 2006: 388). The academic world is well placed to foster that conversation.

Yet, there is still some way to go. The longer term value of complexity depends on our ability to make theoretical and practical progress by fostering interdisciplinary research, 'unpacking' the term 'complexity' further and providing insights using a language 
common to academics and practitioners. To state that political systems are complex is to state the obvious (although to state that they are 'complex systems' is not). The real value of complexity theory may only come from meaningful applications which help solve real policy problems.

Acknowledgements: to Robert Geyer, Stuart Astill, Graham Room and the three anonymous reviewers for comments on previous drafts.

\section{References}

Arenas, A., Diaz-Guilera, A., Kurths, J., Moreno, Y., Zhou, C. (2008) 'Synchronization in complex networks', Physics Reports, 469, 3, 93-153

Axelrod, R. (1984) The Evolution of Cooperation (New York: Basic Books)

Baumgartner, F. and Jones, B. (1993; 2009) Agendas and Instability in American Politics $\left(1^{\text {st }}\right.$ and $2^{\text {nd }}$ editions) (Chicago: University of Chicago Press)

Barrett, S. and Fudge, C., eds (1981) Policy and Action (London: Methuen)

Bevir, M. and Rhodes, R.A.W. (2003) Interpreting British Governance (London:

Routledge)

Bevir, M. and Rhodes, R.A.W. (2006) Governance Stories (London: Routledge)

Blackman, T. (2001) 'Complexity theory and the new public management', Social Issues $1(2)$

Bovaird, T. (2008) 'Emergent Strategic Management and Planning Mechanisms in Complex Adaptive Systems', Public Management Review, 10, 3, 319-40

van Buuren, A. and Gerrits, L. (2008) 'Decisions as Dynamic Equilibriums in Erratic Policy Processes', Public Management Review, 10, 3, 381-99

Butler, M. and Allen, P. (2008) 'Understanding Policy Implementation Processes as SelfOrganizing Systems', Public Management Review, 10, 3, 421-40

Byrne, D. (1998) Complexity Theory and the Social Sciences (London: Routledge)

Cairney, P. (2009) 'Implementation and the Governance Problem: A Pressure Participant Perspective', Public Policy and Administration, 24, 4, 355-77

Cairney, P. (2010a) 'Complexity Theory in Public Policy', Paper to the Political Studies

Associations Conference, University of Edinburgh, April

Cairney, P. (2010b) 'Bridging the Methodological Gap Between the Physical and Social

Sciences: Complexity Theory and Mixed Methods', Paper to the Political Studies

Associations Conference, University of Edinburgh, April

Cairney, P. (2012) Understanding Public Policy: Theories and Issues (Basingstoke:

Palgrave)

Craib, I. (1992) Anthony Giddens (London: Routledge)

Geyer, R. (2012) 'Can Complexity Move UK Policy beyond 'Evidence-Based Policy

Making' and the 'Audit Culture'? Applying a 'Complexity Cascade' to Education and Health Policy', Political Studies, 60, 1, 20-43

Geyer, R. and Rihani, S. (2010) Complexity and Public Policy (London: Routledge) beim Graben, P., Zhou, C., Thiel, M., Kurths, J. (2008) 'Lectures in Supercomputational Neuroscience - Dynamics in Complex Brain Networks' (Heidelberg: Springer) Hallsworth, M. and Rutter, J. (2011) Making Policy Better (London; Institute for Government) 
Hay, C. (2002) Political Analysis: A Critical Introduction (Basingstoke: Palgrave Macmillan)

Haynes, P. (2003) Managing Complexity in the Public Services (Maidenhead: Open University Press)

Haynes, P. (2008) 'Complexity Theory and Evaluation in Public Management', Public

Management Review, 10, 3,401-19

Heclo, H. (1978) 'Issue Networks and the Executive Establishment', in A. King (ed.) The New American Political System (Washington D.C.: American Enterprise Institute)

Hindmoor, I. (2011) 'Review Article: 'Major Combat Operations Have Ended'? Arguing about Rational Choice' British Journal of Political Science, 41, 1, 191-201

Hjern, B., and Porter, D. (1981) 'Implementation Structures: A New Unit of

Administrative Analysis', Organizational Studies 2: pp. 211-27

Jervis, R. (1998) System Effects; Complexity in Political and Social Life (New Jersey: Princeton University Press)

Jones, B. and Baumgartner, F. (2005) The Politics of Attention (Chicago: University of Chicago Press)

Jordan, G. (1981) 'Iron Triangles, Woolly Corporatism and Elastic Nets: Images of the Policy Process', Journal of Public Policy 1, 1, 95-123

Keating, M. (2009) 'Putting European political science back together again', European Political Science Review, 1, 2, 297-316

Kernick, D. (2006) 'Wanted - new methodologies for health service research. Is complexity theory the answer?' Family Practice 23, 385-390

Klijn, E. (2008) 'Complexity Theory and Public Administration: What's New?', Public Management Review, 10,3, 299-317

Lewis, O. and Steinmo, S. (2008) 'Taking Evolution Seriously', European University Institute, Florence

Lewis, O. and Steinmo, S. (2010) 'Taking Evolution Seriously in Political Science', Theory in Biosciences, 129, 2-3, 235-245

Lindblom, C. (1959) 'The Science of Muddling Through', Public Administration Review, 19, 79-88

Lipsky, M. (1980) Street Level Bureaucracy. New York: Russell Sage Foundation

Mahoney, J. and Goertz, G. (2006) 'A Tale of Two Cultures: Contrasting Quantitative and Qualitative Research', Political Analysis, 14, 227-49

Little, A. (2008) Democratic Piety: Complexity, Conflict and Violence (Edinburgh: Edinburgh University Press)

Little, A. (2012) 'Political Action, Error and Failure: The Epistemological Limits of Complexity', Political Studies, 60, 1, 3-19

Marsh, D. (2008) 'Understanding British Government: Analysing Competing Models', British Journal of Politics and International Relations, 10, 2, 251-69

Mitleton-Kelly, E. (2003) 'Ten Principles of Complexity and Enabling Infrastructures' in E. Mitleton-Kelly (ed.) Complex Systems and Evolutionary Perspectives of Organisations (Amsterdam: Elsevier).

Mitchell, M. (2009) Complexity (Oxford: Oxford University Press)

Motter, A., Moura, A., Lai, Y.C. (2002) 'Topology of the conceptual network of language' Phys. Rev. E, 65, 065102

Moura, A., Motter, A., Grebogi, C. (2003) 'Searching in small-world networks', Phys. 
Rev. E, 68, 036106

Newman, M., Barabasi, A.L., Watts, D.J. (2006) The Structure and Dynamics of Networks (Princeton: University Press)

Padgett, J. And McLean, P. (2006) 'Organizational Invention and Elite Transformation: The Birth of Partnership Systems in Renaissance Florence', American Journal of Sociology, 111, 5, 1463-1568

Pierson, P. (2000) 'Increasing Returns, Path Dependence, and the Study of Politics', The American Political Science Review, 94, 2, 251-267

Rhodes, R.A.W. (1997) Understanding Governance (Open University Press)

Richards, D. and Smith, M. (2004) "The 'Hybrid State': Labour's response to the Challenge of Governance" in (eds) Ludlam, S. and Smith, M Governing as New Labour (London: Palgrave)

Richardson, J.J. (2000) 'Government, Interest Groups and Policy Change', Political Studies, 48, 1006-25

Room, G. (2011) Complexity, Institutions and Public Policy (Cheltenham: Edward Elgar) Sanderson, I. (2006) 'Complexity, 'practical rationality' and evidence-based policy making', Policy and Politics, 34, 1, 115-32

Sanderson, I. (2009) 'Intelligent Policy Making for a Complex World: Pragmatism, Evidence and Learning', Political Studies, 57, 699-719

Shine, K. (2006) 'Regenerating Unpopular Social Housing Estates: Can Complexity Theory

Help to Achieve Best Possible Solutions?' Housing, Theory and Society, 23, 2, 65-91

Simon, H. (1976) Administrative Behavior $3^{\text {rd }}$ edition (New York: Free Press)

Teisman, G. and Klijn, E. (2008) 'Complexity Theory and Public Management', Public Management Review, 10, 3,287-97

Thelen, K. and Steinmo, S. (1992) 'Historical Institutionalism in Comparative Politics' in (eds) Steinmo, S., Thelen, K. and Longstreth, F. Structuring Politics: Historical Institutionalism in Comparative Analysis (Cambridge: Cambridge University Press)

Workman, S., Jones, B. and Jochim, A. (2009) 'Information Processing and Policy Dynamics', Policy Studies Journal, 37, 1, 75-92

\footnotetext{
${ }^{i}$ However, we should be careful not to turn rational choice into another straw man. There are two points of comparison between rational choice and complexity that deserve further analysis. First, the methodological individualism often used in RCT suggests that outcomes can be reduced to the level of the individual, but not all accounts do so. Further, we should clarify what we mean when we refer to individual analysis. In sophisticated rational choice accounts, individuals do not operate in a vacuum. Instead, they operate within a structured environment, recognising rules and reacting/ adapting to the behaviour of other individuals. As stated, this is not the polar opposite to complexity theory's focus on interdependent elements which interact with each other, share information and combine to produce systemic behaviour - even if complexity theory suggests that we cannot break such analysis down to the individual. The semantics of such arguments need further analysis. Second, RCT and complexity can both be linked to the pursuit of evolutionary theory (albeit partly because this is an approach, like new institutionalism, with many variants). For example, Lewis and Steinmo (2008) use evolutionary arguments to largely reject RCT, but they also acknowledge (with reference to Axelrod, 1984) the value of evolutionary game theory and the centrality of the trial-anderror strategies of individuals to accounts of generational change in political science.

ii See also Klijn (2008) for a link to the literature on governance, multiple streams analysis and game theory.
} 
iii For example, many of these terms may be used in areas such as computing science or systems biology to explore unpredictability, while path dependence and sensitivity to initial conditions in historical institutionalism may often be more about explaining stability.

${ }^{\text {iv }}$ Frank Baumgartner is also developing work which explores 'power laws' more directly. See for example http://www.unc.edu/ fbaum/papers/Budgets_as_Power_Laws_2009.pdf

and http://www.unc.edu/ fbaum/Innocence/Baumgartner-Power-Law-of-Death-gtown.pdf

${ }^{v}$ See also Haynes (2008: 402): 'Complexity accepts the inevitability that individuals are often subservient to social structures, but realizes that feedback from individuals, however, small in power, can contribute in unpredictable ways to the future organization and representation of structures'. 